\title{
The factors associated with distress following exposure to smoke from an extended coal mine fire
}

Jonathan C. Broder ${ }^{a}$, Caroline Gao ${ }^{a, b}$, Timothy C. H. Campbell ${ }^{c}$, Emily Berger ${ }^{d}$, Darryl Mayberye, Alexander McFarlanef, Jessica Tsoutsoulise, Jillian Ikina, Michael J. Abramsona, Malcolm R. Sima, Judi Walker ${ }^{c}$, Ashok Luharg, Matthew Carrollc

\section{Affiliations}

${ }^{a}$ Department of Epidemiology and Preventive Medicine, School of Public Health and Preventive Medicine, Monash University, 553 ST Kilda Road, Melbourne, Victoria, 3004, Australia

${ }^{b}$ Orygen, Centre for Youth Mental Health, The University of Melbourne, Parkville, VIC, Australia

${ }^{c}$ Monash Rural Health Churchill, Monash University, Northways Road, Churchill, Victoria, 3842, Australia

${ }^{d}$ Faculty of Education, Monash University, 29 Ancora Imparo Way, Clayton, Victoria, 3800, Australia

e Monash Rural Health, Monash University, 15 Sargeant Street, Warragul, Victoria, 3820, Australia

${ }^{f}$ Centre for Traumatic Stress Studies, The University of Adelaide, 30 Frome Road, South Australia, 5005, Australia

${ }^{\mathrm{g}}$ Aerosol and Chemistry Modelling, Climate Science Centre, CSIRO Oceans and Atmosphere, 107-121

Station Street, Aspendale, Victoria, 3195, Australia

\section{Corresponding Author}

Dr Matthew Carroll

Monash Rural Health Churchill, Monash University, C/- Federation University, Northways Road, Churchill, Victoria, Australia

Telephone: 61351227604

Fax: 61351227841

Email: matthew.carroll@monash.edu

\section{Note}

This is the final accepted version of a paper which has been published by Environmental Pollution. The full citation for the published paper is as follows:

Broder, J. C., Gao, C. X., Campbell, T. C. H., Berger, E., Maybery, D., McFarlane, A., Tsoutsoulis, J., Ikin, J. F., Abramson, M. J., Sim, M. R., Walker, J., A, L., \& Carroll, M. (2020). The factors associated with distress following exposure to smoke from an extended coal mine fire. Environmental Pollution, 266, part 2, November 2020, 115131. https://doi.org/10.1016/j.envpol.2020.115131 


\begin{abstract}
In February 2014, the coalmine adjacent to the Hazelwood Power Station in the Latrobe Valley of Victoria, Australia, caught fire, with residents from the nearby town of Morwell and the wider area exposed to smoke for six weeks. Although there was evidence linking the mine-fire event with psychological distress, no studies have evaluated the degree of distress in relation to the level of smoke exposure. We aimed to investigate the exposure-response relationship between particulate matter $2.5 \mu \mathrm{m}$ or less in diameter $\left(\mathrm{PM}_{2.5}\right)$ released during the Hazelwood mine fire event and long-term symptoms of posttraumatic distress in the affected community, including the consideration of other key factors. A total of 3,096 Morwell residents, and 960 residents from the largely unexposed comparison community of Sale, were assessed for symptoms of posttraumatic distress 2.5 years after the Hazelwood incident using the Impact of Events Scale-Revised (IES-R). Individual-level PM 2.5 exposure was estimated by mapping participants' self-reported location data on modelled $\mathrm{PM}_{2.5}$ concentrations related to the mine fire. Multivariate linear regression was used to evaluate the exposure-response relationship. Both mean and peak exposure to mine fire-related $\mathrm{PM}_{2.5}$ were found to be associated with participant IES-R scores with an interaction effect between age and mean $\mathrm{PM}_{2.5}$ exposure also identified. Each $10 \mu \mathrm{g} / \mathrm{m}^{3}$ increase in mean $\mathrm{PM}_{2.5}$ exposure corresponded to a 0.98 increase in IES-R score (95\% Cl: 0.36 to 1.61), and each $100 \mu \mathrm{g} / \mathrm{m}^{3}$ increase in peak $\mathrm{PM}_{2.5}$ exposure corresponded to a 0.36 increase $(95 \% \mathrm{Cl}: 0.06$ to 0.67$)$. An age-effect was observed, with the exposureresponse association found to be stronger for younger adults. The results suggest that increased exposure to $\mathrm{PM}_{2.5}$ emissions from the Hazelwood mine fire event was associated with higher levels of psychological distress associated with the mine fire and the most pronounced effect was on younger adults living in the affected community.
\end{abstract}

\title{
Main findings:
}

There is an exposure-response relationship between $\mathrm{Pm}_{2.5}$ released from the Hazelwood mine fire event and long-term psychological distress towards the event. The exposure-response relationship is more pronounced in younger adults than older adults.

\section{Keywords:}

Posttraumatic Distress; Mine Fire; Air Pollution; $\mathrm{PM}_{2.5}$ Exposure; Cross-Sectional Study 


\section{Introduction}

During February 2014, the open-cut coalmine adjacent to the Hazelwood Power Station in the Latrobe Valley region of Victoria, Australia caught fire due to nearby wildfires. The resulting Hazelwood mine fire burnt for approximately six weeks, releasing smoke into the air of the surrounding areas, particularly the adjacent town of Morwell (see Figure 1 for map). During the mine fire event, the estimated hourly averaged concentrations of fine particulate matter $2.5 \mu \mathrm{m}$ or less in diameter $\left(\mathrm{PM}_{2.5}\right)$ was as high as $3700 \mu \mathrm{g} \mathrm{m} \mathrm{m}^{3}$ in Morwell, which was well above the estimated average background $\mathrm{PM}_{2.5}$ concentrations of $6 \mu \mathrm{g} / \mathrm{m}^{3}$ for the town (Emmerson, Reisen, Luhar, Williamson, \& Cope, 2016). Residents of the Latrobe Valley initially expressed their concern about the effects of the coalmine fire on their physical health (Wood et al., 2015), with a number of individuals reporting non-specific symptoms such as headaches, nausea and dizziness, as well as psychological distress towards the event. Consequent to the mine fire, the Hazelwood Health Study (HHS; hazelwoodhealthstudy.org.au) was established to investigate the long-term impact of the mine fire smoke on the health and wellbeing of nearby communities.

Smoke released from coalmine fires is composed of many pollutants, including particulate matter and carbon monoxide, which are hazardous to human health (Melody \& Johnston, 2015). In the context of psychological health, exposure to $\mathrm{PM}_{2.5}$ has been associated with an increased risk of both general and phobia-related anxiety (Power et al., 2015), depression (Kioumourtzoglou et al., 2017; Ren, Yu, \& Yang, 2019), and general psychological distress (Gu, Yan, Elahi, \& Cao, 2020; Sass et al., 2017) regardless of the individual's awareness of their exposure. However, to date, very limited research has investigated the impact of exposure to smoke emanating from coalmine fires on psychological health (Jones, Lee, Maybery, \& McFarlane, 2018; Maybery et al., 2020).

The Centralia coalmine fire in Pennsylvania, USA, has been burning since at least 1962, and is reported to have resulted in elevated distress and mental instability in members of that community (Kroll-Smith, 1990). Earlier qualitative research undertaken by the HHS (Jones et al., 2018) found that residents in Morwell had experienced uncertainty and ambivalence during the prolonged Hazelwood mine fire event, which was likely to have had an adverse impact on their psychological health. In a larger, epidemiological study, the HHS compared the psychological health of individuals from Morwell with a control-group of residents from the relatively unexposed, but otherwise demographically similar, town of Sale (Maybery et al., 2020). The researchers found that, more than two years after the Hazelwood mine fire event, Morwell residents experienced significantly more distress specifically related to the incident (also known as posttraumatic distress or event-related distress) than Sale residents. However, no research to date has established an exposure-response relationship between the level of exposure to mine fire smoke and the degree of posttraumatic distress.

The current research aimed to investigate the effects of varying levels of exposure to $\mathrm{PM}_{2.5}$ released from the Hazelwood mine fire event on the development of long-term symptoms of posttraumatic distress, as well as the contribution of other known risk factors such as age, prior mental health and traumatic exposures, and chronic respiratory and cardiovascular conditions. Based on the observed relationship between $\mathrm{PM}_{2.5}$ exposure and psychopathology (Gu et al., 2020; Kioumourtzoglou et al., 2017; Power et al., 2015; Ren et al., 2019; Sass et al., 2017), and existing evidence of the psychological impact of mine fire disasters (Jones et al., 2018; Kroll-Smith, 1990; Maybery et al., 2020), we hypothesised that a positive exposure-response relationship would be observed between levels of $\mathrm{PM}_{2.5}$ exposure and symptoms of posttraumatic distress. Morwell residents were also compared to residents from Sale to assess for any impact of residing in Morwell at the time of the event over and above the distress attributable to $\mathrm{PM}_{2.5}$ exposure. Furthermore, we hypothesised that other factors, such as age, and prior health trajectories, would impact on the relationship between $\mathrm{PM}_{2.5}$ and event-related distress. 


\section{Methods}

\section{Study design}

The current research is part of the HHS Adult Survey, which is a cross-sectional study that aimed to assess the health effects of the Hazelwood mine fire event on a sample of Morwell adults in comparison to adults from targeted areas of Sale. The comparison community was selected on the basis of having had negligible exposure to the smoke from the Hazelwood coal mine fire (Emmerson et al., 2016), an adequate population size, and being closely matched to the sociodemographic profile of Morwell in terms of SEIFA rankings (Australian Bureau of Statistics, 2012). In order to maximise comparability, only people living in one of the 16 ABS Statistical Areas level 1 (SA1s) of Sale with the lowest SEIFA scores were invited to participate. In Sale, the hourly averaged $\mathrm{PM}_{2.5}$ concentrations during the mine fire event only reached a maximum of 17 $\mu \mathrm{g} / \mathrm{m}^{3}$, and the estimated background $\mathrm{PM}_{2.5}$ concentrations were similar to that of Morwell (approximately $\left.6 \mu \mathrm{g} / \mathrm{m}^{3}\right)$.

A total of 13,892 residents were identified from the electoral roll maintained by the Victorian Electoral Commission as eligible for inclusion in the study. To be eligible for the study, participants had to be 18 years or older on the $31^{\text {st }}$ of March 2014. 3,096 Morwell residents and 960 Sale residents were recruited for the Adult Survey, reflecting participation rates of $34 \%$ and $23 \%$ respectively. The Adult Survey, which commenced in May 2016 and concluded in mid-February 2017, collected information on participants' characteristics, including sociodemographic details, physical and mental health diagnoses, prior traumatic experiences, and psychological distress related to the mine fire event. Participant recruitment in the HHS Adult Survey included direct contact methods such as mailed invitations, reminder-packs and follow up phone calls, as well as indirect methods such as flyers, media engagement and public events (see Abramson et al. (2017) for additional details about the HHS Adult Survey).

The current research used data from the Adult Survey as well as data on participants' estimated $\mathrm{PM}_{2.5}$ exposure during the mine fire event. Furthermore, the current analysis considered the role of other variables on the exposure-response relationship, such as age, prior mental health, prior traumatic exposures, and chronic health conditions.

\section{Measures}

Data was collected primarily by self-report questionnaire.

\section{The Impact of Events Scale-Revised}

The psychological outcome measure was the Impact of Events Scale-Revised (IES-R) (Weiss \& Marmar, 1997), which measured the participant's subjective psychological distress specifically in relation to the Hazelwood mine fire incident. The IES-R is composed of 22 items scored on a 0-4 scale $(0=$ Not at all; $1=A$ little bit; 2 = Moderately; 3 = Quite a bit; 4 = Extremely). These items are grouped into three subscales (Intrusion, Avoidance and Hyperarousal) relating to 14 of the 17 symptoms of PTSD from the Diagnostic and Statistical Manual of Mental Disorders, 4th Edition. The present study used participant's total score on the IES-R (range: 0-88).

\section{Mine fire exposure}

High resolution, hourly mine fire-related $\mathrm{PM}_{2.5}$ concentrations were modelled retrospectively by the Commonwealth Scientific and Industrial Research Organisation (CSIRO) Oceans and Atmosphere Flagship (Emmerson et al., 2016). The modelled mine fire-related $\mathrm{PM}_{2.5}$ concentrations were then mapped to each participants' self-reported 12-hourly location diary of their residential, work or relocation addresses during the mine fire event ( $9^{\text {th }}$ February 2014 to $31^{\text {st }}$ March 2014). The mean exposure to $P M_{2.5}$ was derived by averaging each participant's 12-hourly exposure based on their location diary, thus reflecting the participant's mean $\mathrm{PM}_{2.5}$ exposure throughout the entire mine fire period. The peak exposure to $\mathrm{PM}_{2.5}$ was 
determined as the highest 12-hourly concentration value to which a participant was exposed at any of the diary addresses, regardless of the amount of time the individual was exposed. For simplicity, mean exposure to $\mathrm{PM}_{2.5}$ over the mine fire period will be referred to as 'mean' $\mathrm{PM}_{2.5}$ exposure, while the participant's peak $\mathrm{PM}_{2.5}$ exposure will simply be referred to as 'peak' $\mathrm{PM}_{2.5}$ exposure. See Blackman et al. (2018) for more details about the $\mathrm{PM}_{2.5}$ exposure estimation.

\section{Prior traumatic exposures}

To capture participants' exposure to prior traumatic experiences, a list of 11 traumatic exposures from the posttraumatic distress disorder (PTSD) module of the Composite International Diagnostic Interview (CIDI) Version 2.1 (Goldney, Wilson, Dal Grande, Fisher, \& McFarlane, 2000) was used. The list of traumatic experiences included physical attack, rape, life-threatening accidents, and other extremely stressful events experienced by the participant or close associates. The number of prior traumatic exposures each participant reported was tallied and then categorised as: (1) no traumatic events, (2) one traumatic event, or (3) multiple traumatic events.

\section{Self-reported doctor-diagnosed conditions}

Participants self-reported doctor-diagnosed cardiovascular conditions (heart attack, heart failure, angina, irregular heart rhythm, stroke or other heart disease), respiratory conditions (asthma and chronic obstructive pulmonary disease [COPD]), and mental health conditions (anxiety, depression, posttraumatic stress disorder, or other mental health conditions) along with year first diagnosed. These medical conditions were classified as categorical variables with three levels: (1) no condition; (2) prior to the mine fire (first diagnosed in 2013 or earlier) and (3) post mine fire (first diagnosed in 2014 or later).

\section{Binge drinking}

Binge drinking (heavy episodic drinking) was assessed using the binge drinking item from the Alcohol Use Disorders Identification Test (AUDIT C) (Bush, Kivlahan, McDonell, Fihn, \& Bradley, 1998). The binge drinking item was utilised to measure how frequently participants consumed more than six standard drinks on a single occasion, ranging from 0 (Never) to 5 (Daily or almost daily) (Foxcroft, Moreira, Almeida Santimano, \& Smith, 2015).

\section{Occupational exposure}

Participants were asked to report any job that they had held for 6 months or more that involved exposure to fumes, dust, smoke, mist or gas vapour, including whether they had worked in the Latrobe Valley coal mines or power stations (excluding office-based jobs) for at least 6 months. Based on this information, participants were determined as either being occupationally exposed at a coal mine or power station, occupationally exposed but not at a coal mine or power station, or not occupationally exposed.

\section{Ethics approval}

The protocol for the research was approved by the Monash University Human Research Ethics Committee (MUHREC) for the period 21 May 2015 to 21 May 2020 (MUHREC Project number CF15/872). All participants provided informed consent.

\section{Statistical analysis}

A total of 4,056 Adult Survey participants from both Morwell and Sale were included in these analyses. Possible response biases were evaluated based on 2011 Census data (Australian Bureau of Statistics, 2012) and Victorian Population Health Survey 2011-12 data (Department of Health, 2014), and post-stratification weighting by gender and age group ( 5 years) were applied. Missing data, which ranged from $0-5.79 \%$ for 
the Adult Survey data (for the questions included in the analysis) and $0 \%$ for the $\mathrm{PM}_{2.5}$ data, were handled using multiple imputation (Rubin, 1996) by chained equations, using the ICE package under Stata MI procedures (Royston \& White, 2011).

Descriptive statistics were calculated for Sale (as the no exposure comparison community) and low, medium and high exposure groups in Morwell based on mean $\mathrm{PM}_{2.5}$ exposure tertiles (of Morwell residents only). Categorical variables were presented as counts and percentages, while numeric variables were represented as means and standard deviations, or medians and inter-quartile ranges (IQR) for the IES-R, as the score distribution was heavily skewed for this measure. Crude differences in characteristics between low, medium and high exposure groups in Morwell and Sale participants were compared using Pearson chisquared tests for categorical variables and t-tests for numeric variables. The skewed IES-R was analysed with the nonparametric Somers' D statistic (Newson, 2006).

The relationships between IES-R and mean and peak exposure to $\mathrm{PM}_{2.5}$ were assessed using two separate multivariate linear regression analysis models. To improve the interpretability of the results, mean and peak $\mathrm{PM}_{2.5}$ were scaled per $10 \mu \mathrm{g} / \mathrm{m}^{3}$ and $100 \mu \mathrm{g} / \mathrm{m}^{3}$, respectively. All models accounted for poststratification weights and clustering at the household level (Blackman et al., 2018). The participant characteristics, age, sex, employment, education, prior mental health conditions, prior traumatic exposures, asthma, COPD, cardiac events, frequency of binge drinking ( 6 or more standard drinks in one occasion), and occupational exposure were accounted for in the models as potentially confounding variables. We included the participant township variable (Morwell vs. Sale) in the regression models to evaluate the township effect when controlling for exposure level. This provides useful information regarding whether Morwell participants experienced any event-related distress in the absence of exposure to the mine fire smoke, as some Morwell residents (e.g. those who moved during the mine fire event) would have had little to no $\mathrm{PM}_{2.5}$ exposure. Interaction effects between the confounding variables and mean and peak exposure to $\mathrm{PM}_{2.5}$ were then evaluated. Sensitivity analysis was also performed by removing Sale from the model, as well as analysing a natural log transformed IES-R $(+1$, as there were 0 values).

Due to the inclusion of an interaction effect between age and mean and peak $\mathrm{PM}_{2.5}$ exposure in the regression models, age was centred at the mean (57 years), and mean and peak $\mathrm{PM}_{2.5}$ were centred at the $10 \mu \mathrm{g} / \mathrm{m}^{3}$ and $100 \mu \mathrm{g} / \mathrm{m}^{3}$, respectively. This allowed for main effect estimates of mean and peak $\mathrm{PM}_{2.5}$ on IES-R scores at the mean age of the cohort, as well as main effect estimates of age on IES-R scores at 10 $\mu \mathrm{g} / \mathrm{m}^{3}$ and $100 \mu \mathrm{g} / \mathrm{m}^{3}$ for mean and peak $\mathrm{PM}_{2.5}$, respectively. Predictive marginal plots were made using marginal estimates for every $20 \mu \mathrm{g} / \mathrm{m}^{3}$ of mean $\mathrm{PM}_{2.5}$ exposure (from 0 to $80 \mu \mathrm{g} / \mathrm{m}^{3}$ ) and at ages $20,40,60$ and 80 years, with other predictors at the mean value (for continuous variables) or the reference category (for categorical variables). All analyses were conducted using Stata version 15 (StataCorp, 2017).

\section{Results}

\section{Participants' characteristics}

Table 1 presents the characteristics of Morwell exposure groupsError! Reference source not found. and Sale participants. Participants from the Morwell exposure groups and Sale were broadly comparable on age, gender, presence of prior mental health conditions, number of traumatic exposures, and proportions with cardiovascular disease and binge drinking behaviour. However, compared with Sale participants, those from Morwell were more likely to have a lower level of education and to be unemployed or unable to work, with little differences observed between each Morwell exposure group. A higher proportion of Morwell participants had coal mine/station occupational exposure and self-reported diagnoses of asthma or COPD (both pre- and post-fire). Within Morwell exposure groups, there were also no obvious differences in occupational exposure, asthma and COPD. IES-R scores were observed to be higher on average in the higher exposure groups. 
Figure 2 illustrates the distributions of IES-R scores for Sale compared to low, medium and high exposure groups in Morwell. Peak $\mathrm{PM}_{2.5}$ exposure was higher in the higher exposure groups, reflecting the correlation between mean and peak $\mathrm{PM}_{2.5}$ exposure. The relationship between IES-R scores and $\mathrm{PM}_{2.5}$ exposure, for both Morwell and Sale residents, as well as the univariate distribution of these variables, is demonstrated in Figure 3 and

Figure 4 for mean and peak $\mathrm{PM}_{2.5}$ exposure, respectively. Figure $\mathrm{S} 1$ (see supplementary material) illustrates the relationship and distributions between mean and peak $\mathrm{PM}_{2.5}$ exposure grouped by IES-R scores within the $75^{\text {th }}$ percentile (IES-R $\leqslant 8$ ) and outside the $75^{\text {th }}$ percentile (IES-R $>8$ ) for Morwell residents only.

Exposure-response relationship between $\mathrm{PM}_{2.5}$ exposure and IES-R scores 
Table 2 displays the results of the multivariate regression models for the effect of increases in mean and peak $\mathrm{PM}_{2.5}$ exposure on change in IES-R score. When controlling for potentially confounding variables, increases in both mean and peak $\mathrm{PM}_{2.5}$ exposures were found to be associated with increases in IES-R scores. A negative interaction was identified between age and mean $\mathrm{PM}_{2.5}$ exposure, but not peak $\mathrm{PM}_{2.5}$ exposure. For every $10 \mathrm{\mu g} / \mathrm{m}^{3}$ increase in mean $\mathrm{PM}_{2.5}$ exposure, there was a 0.98 (95\% Cl: 0.36 to 1.61) increase in IES-R score at the mean age (57 years) of the cohort. At the age of 20 , the estimated effect size was almost doubled with a 1.96 score increase in IES-R ( $95 \% \mathrm{Cl}: 0.57$ to 3.36$)$ per $10 \mu \mathrm{g} / \mathrm{m}^{3}$ increase in mean $\mathrm{PM}_{2.5}$ exposure. The predictive marginal plot of this interaction effect between mean exposure to $\mathrm{PM}_{2.5}$ and IES-R is shown in Figure 5. For every $100 \mu \mathrm{g} / \mathrm{m}^{3}$ increase in peak $\mathrm{PM}_{2.5}$ exposure, there was a 0.36 (95\% Cl: 0.06 to 0.67$)$ increase in IES-R at the mean age (57) of the cohort, which was estimated similarly across age groups. Exploratory analysis (not presented) revealed no other significant interactions between the other confounding variables and either mean or peak $\mathrm{PM}_{2.5}$ exposure. Furthermore, the sensitivity analysis of the log transformed IES-R scores (not presented) and the analysis on Morwell only (see Table S 1 and Figure S 2) were congruent with the aforementioned findings.

Participants in Morwell were found to have higher IES-R scores than those from Sale after controlling for exposure level and other potentially confounding variables. Being younger, with lower educational levels, unemployed or unable to work and having experienced multiple historical traumatic exposures were also found to be independently associated with higher IES-R scores. Chronic health conditions, including having any mental health condition, or either a pre- or post-fire diagnosis of asthma or COPD, were also independently associated with higher IES-R scores. There were no associations found between binge drinking, cardiovascular disease, or occupational exposure and IES-R scores.

\section{Discussion}

This research identified an exposure-response relationship between participants' exposure to $\mathrm{PM}_{2.5}$ and their self-reported symptoms of posttraumatic distress related to the Hazelwood mine fire event. This finding suggests that adults who were heavily exposed to the coalmine fire generally experienced more symptoms of posttraumatic distress two and half years after the mine fire event, compared to adults who were less exposed. The exposure-response relationship was present after accounting for potentially confounding variables, including participants' age, prior mental health, sex, education, employment status, number of traumatic exposures, binge drinking behaviour, presence of asthma, COPD, cardiovascular disease, occupational exposure, and township. Further, the estimated exposure-response relationship was also greater in younger adults, meaning that younger adults were more sensitive to $\mathrm{PM}_{2.5}$ exposure compared to older adults.

Although past research has shown that exposure to ambient $\mathrm{PM}_{2.5}$ is positively associated with psychopathological symptoms (Gu et al., 2020; Kioumourtzoglou et al., 2017; Power et al., 2015; Ren et al., 2019; Sass et al., 2017), the current research extends this observation by revealing a clear exposureresponse relationship between mine fire emitted $\mathrm{PM}_{2.5}$ and posttraumatic distress. As theorised by Block and Calderón-Garcidueñas (2009), the relationship between PM 2.5 exposure and PTSD symptoms may be due to nervous system changes in those who were exposed. Alternatively, it may be due to behavioural changes, such as reduced physical activity (Goodwin, 2003) or greater time spent indoors (Bresnahan, Dickie, \& Gerking, 1997). As there is significant evidence linking pollution exposure to respiratory illness (Delfino, 2002), it is possible that the association between exposure and PTSD symptoms is also related to the aggravation of pre-existing respiratory conditions or development of new respiratory conditions post the event. The analysis showed that asthma and COPD, diagnosed both prior to and following the exposure event, were associated with increased event-related distress. However, the exposure-response relationship persisted after controlling for these respiratory conditions diagnosed before and after the mine fire. There is also no evidence that the exposure-response relationship varied between those with respiratory 
conditions diagnosed prior to the fire and those without such conditions. These findings suggest that factors other than respiratory conditions impacted on the exposure-response relationship.

It is likely that there are multiple causal pathways driving the exposure-response relationship, with posttraumatic distress also likely to be associated with the perceived threat from the smoke exposure in addition to the direct toxic effects. It has been argued that uncertainty to do with the degree and type of exposure and about the potential health outcomes, can impact on the perceived threat from an exposure event and the resultant psychological outcomes (Green, 1998). The potential for man-made or technological disasters to have a greater impact on psychological health compared with natural disasters, because of the perceived breach of the social contract between the responsible agencies and the community, has also been proposed (Green, 1998). All of these factors are relevant to the Hazelwood mine fire event.

Morwell residents scored higher on the IES-R scale than Sale residents after accounting for the level of $\mathrm{PM}_{2.5}$ exposure and other potentially confounding variables. This suggests that those Morwell residents who had little or no exposure to $\mathrm{PM}_{2.5}$ (perhaps due to having left the area prior to or during the smoke event), still reported higher levels of event-related distress, on average, than Sale residents. The finding that locality was associated with posttraumatic distress independent of individuals' level of exposure to smoke during the mine fire provides some evidence to suggest that distress was also potentially determined by people's appraisals of the impact of the event on the Morwell community, including wider health, socioeconomic, and social outcomes.

Further, the current analysis also sheds considerable light on the role of individual characteristics in the development of posttraumatic distress, with age in particular shown to be an important moderating factor. The effect of $\mathrm{PM}_{2.5}$ exposure on posttraumatic distress was worse in younger adults and younger adults also reported higher levels of posttraumatic distress regardless of $\mathrm{PM}_{2.5}$ exposure. There are multiple, potentially intersecting, pathways for this increase in the level of response to stressful events in younger people. Firstly, younger individuals typically have less experience coping with natural disasters, and those with less experience are more psychologically vulnerable (Knight, Gatz, Heller, \& Bengtson, 2000). Other research suggests that age-related changes in the prefrontal cortex, including hippocampal atrophy, may reduce the level of responsiveness to stressful events (Andrews et al., 2017; Novais, Monteiro, Roque, Correia-Neves, \& Sousa, 2017). The converse finding that older people were less likely to report symptoms of event-related distress whereas those with asthma, COPD, mental health conditions, or not working due to ill-health, were more likely to report event-related distress, suggests that there is a need to discriminate between the effect of age and ill health.

Interestingly, the moderating effect of age in the current study was only present for mean, and not peak, exposure to $\mathrm{PM}_{2.5}$. This is likely due to the differences in the measurement of mean and peak exposure, with peak exposure being the maximum exposure for individuals during the event which varied markedly depending on location, whereas mean exposure was the average of 12-hourly exposure across the entire period and so was a marker of cumulative exposure. As such, mean exposure may be more sensitive to psychological outcomes than a single acute spike in $\mathrm{PM}_{2.5}$.

The present analysis also showed that IES-R scores were related to a number of demographic and health variables, lending support to several previous research findings. Those with higher education levels (Bonanno, Galea, Bucciarelli, \& Vlahov, 2007; Greene, Neria, \& Gross, 2016) had lower symptoms of posttraumatic distress, while those who were unemployed or unable to work (Greene et al., 2016), had prior mental health conditions (Perrin et al., 2014), previous experience of multiple traumatic exposures (Bodvarsdottir \& Elklit, 2004; North, Hong, Suris, \& Spitznagel, 2008), or had been diagnosed with asthma or COPD appeared to have greater symptoms of posttraumatic distress (Arcaya, Lowe, Rhodes, Waters, \& Subramanian, 2014). The time of asthma diagnosis was also important, as the effect of asthma on 
posttraumatic distress was greater for those who were diagnosed with the condition after the mine fire, compared with those who had been diagnosed prior to the mine fire.

This research has a number of noteworthy strengths. In contrast to previous epidemiological studies of pollution events, where associations between exposure and health risks were largely examined at a population level, in the current analysis the association was specifically evaluated at an individual level. In particular, the use of modelled exposure data coupled with participants' location diaries provided a measure of individual PM $_{2.5}$ exposure which was largely free from the influence of the individual's perception of the exposure (Glass \& Sim, 2006). The study also used a large sample of the Morwell and Sale community, as well as accounting for and exploring the impact of a number of known risk factors, such as asthma.

However, there are recognised limitations of the research. Firstly, there is potential for recall bias in the location diary information provided by participants, particularly given that this information was collected more than two years after the mine fire (Coughlin, 1990). Additionally, sampling bias (participation or selection) may still be present even after the application of sampling weightings that was used in the statistical analyses. There was also potential for response bias in the self-reported doctor diagnosed conditions. While self-report survey was the only possible method for collecting this data for such a large group, the limitations of self-reported diagnosis data is well-recognised (Althubaiti, 2016). In addition, data were not collected on factors such as whether the participant had any family member working in the coal mine and level of support they obtained after the mine fire, which may confound the association observed.

\section{Conclusion}

The current analysis is unique in showing a clear exposure-response relationship between objective measurements of pollution exposure and the risk of experiencing symptoms of posttraumatic distress. The analysis also sheds light on the wide range of factors which contribute to levels of vulnerability for experiencing symptoms of distress related to exposure to a community-wide pollution event, including prior mental health and traumatic exposures, chronic health conditions, education and employment status. This provides important insights into vulnerable groups who should be considered by services responding to community needs in the aftermath of pollution events. Importantly, the association between $\mathrm{PM}_{2.5}$ from the Hazelwood mine fire event and posttraumatic distress was more apparent in younger adults. Overall, these findings highlight the need for a more nuanced understanding of vulnerability to psychological distress both during and following disaster events, in order to better support the mental health of members of affected communities. 


\section{Acknowledgments}

The Hazelwood Health Study is a large program of work that comprises a number of research streams in addition to this Adult Survey stream. Those research streams are run by a multidisciplinary group of academic and professional staff from several Institutions including Monash University, the University of Tasmania, Federation University, University of Adelaide and the Commonwealth Scientific and Industrial Research Organisation. All of these staff are thanked for their contribution to this collaborative work. Professor Rory Wolfe is also acknowledged for being an external reviewer of the research. 


\section{References}

Abramson, M., Blackman, J., Carroll, M., Dimitriadis, C., Del Monaco, A., Dennekamp, M., ... Walker, J. (2017). Hazelwood Health Study Adult Survey: Volume 1 Comparison of Morwell and Sale. Retrieved from Melbourne/Victoria/Australia: www.hazelwoodhealthstudy.org.au/study-reports

Althubaiti, A. (2016). Information bias in health research: definition, pitfalls, and adjustment methods. J Multidiscip Healthc, 9, 211-217. https://doi.org/10.2147/JMDH.S104807

Andrews, C., Nettle, D., Larriva, M., Gillespie, R., Reichert, S., Brilot, B. O., . . Bateson, M. (2017). A marker of biological age explains individual variation in the strength of the adult stress response. $R$ Soc Open Sci, 4(9), 171208. https://doi.org/10.1098/rsos.171208

Arcaya, M. C., Lowe, S. R., Rhodes, J. E., Waters, M. C., \& Subramanian, S. V. (2014). Association of PTSD symptoms with asthma attacks among hurricane Katrina survivors. Journal of Traumatic Stress, 27(6), 725-729. https://doi.org/10.1002/jts.21976

Australian Bureau of Statistics. (2012). 2011.0.55.001 Information paper: Census of population and housing - Products and services, 2011. In.

Blackman, J., Carroll, M., Gao, C., Del Monaco, A., Brown, D., Guo, Y., ... Abramson, M. (2018). Hazelwood Health Study Adult Survey: Volume 2 The relationship between Hazelwood mine fire smoke exposure and health outcomes. Retrieved from Melbourne/Victoria/Australia: www.hazelwoodhealthstudy.org.au/study-reports

Block, M. L., \& Calderon-Garciduenas, L. (2009). Air pollution: mechanisms of neuroinflammation and CNS disease. Trends in Neurosciences, 32(9), 506-516. https://doi.org/10.1016/j.tins.2009.05.009

Bodvarsdottir, I., \& Elklit, A. (2004). Psychological reactions in Icelandic earthquake survivors. Scandinavian Journal of Psychology, 45(1), 3-13. https://doi.org/10.1111/j.1467-9450.2004.00373.x

Bonanno, G. A., Galea, S., Bucciarelli, A., \& Vlahov, D. (2007). What predicts psychological resilience after disaster? The role of demographics, resources, and life stress. Journal of Consulting and Clinical Psychology, 75(5), 671-682. https://doi.org/10.1037/0022-006X.75.5.671

Bresnahan, B. W., Dickie, M., \& Gerking, S. (1997). Averting behavior and urban air pollution. Land Economics, 73(3), 340-357. https://doi.org/10.2307/3147172

Bush, K., Kivlahan, D. R., McDonell, M. B., Fihn, S. D., \& Bradley, K. A. (1998). The AUDIT alcohol consumption questions (AUDIT-C): an effective brief screening test for problem drinking. Ambulatory Care Quality Improvement Project (ACQUIP). Alcohol Use Disorders Identification Test. Archives of Internal Medicine, 158(16), 1789-1795. https://doi.org/10.1001/archinte.158.16.1789

Coughlin, S. S. (1990). Recall bias in epidemiologic studies. Journal of Clinical Epidemiology, 43(1), 87-91. https://doi.org/10.1016/0895-4356(90)90060-3

Delfino, R. J. (2002). Epidemiologic evidence for asthma and exposure to air toxics: linkages between occupational, indoor, and community air pollution research. Environmental Health Perspectives, 110, 573-589. https://doi.org/10.1289/ehp.02110s4573

Department of Health. (2014). Victorian Population Health Survey 2011-12, survey findings. (50). State Government of Victoria, Melbourne: State Government of Victoria, Melbourne

Emmerson, K., Reisen, F., Luhar, A., Williamson, G., \& Cope, M. (2016). Air quality modelling of smoke exposure from the Hazelwood mine fire. Retrieved from CSIRO Australia:

Foxcroft, D. R., Moreira, M. T., Almeida Santimano, N. M., \& Smith, L. A. (2015). Social norms information for alcohol misuse in university and college students. Cochrane Database of Systematic Reviews(12), CD006748. https://doi.org/10.1002/14651858.CD006748.pub4

Glass, D. C., \& Sim, M. R. (2006). The challenges of exposure assessment in health studies of Gulf War veterans. Philosophical Transactions of the Royal Society of London. Series B: Biological Sciences, 361(1468), 627-637. https://doi.org/10.1098/rstb.2006.1822

Goldney, R. D., Wilson, D., Dal Grande, E., Fisher, L. J., \& McFarlane, A. C. (2000). Suicidal ideation in a random community sample: attributable risk due to depression and psychosocial and traumatic events. Australian and New Zealand Journal of Psychiatry, 34(1), 98-106. https://doi.org/10.1046/j.1440-1614.2000.00646.x

Goodwin, R. D. (2003). Association between physical activity and mental disorders among adults in the United States. Preventive Medicine, 36(6), 698-703. https://doi.org/10.1016/S0091-7435(03)000422 
Green, B. L. (1998). Psychological responses to disasters: Conceptualization and identification of high-risk survivors. Psychiatry and Clinical Neurosciences, 52(S1), S27-S33. https://doi.org/10.1046/j.14401819.1998.0520s5S67.x

Greene, T., Neria, Y., \& Gross, R. (2016). Prevalence, Detection and Correlates of PTSD in the Primary Care Setting: A Systematic Review. Journal of Clinical Psychology in Medical Settings, 23(2), 160-180. https://doi.org/10.1007/s10880-016-9449-8

Gu, H., Yan, W., Elahi, E., \& Cao, Y. (2020). Air pollution risks human mental health: an implication of twostages least squares estimation of interaction effects. Environmental Science and Pollution Research International, 27(2), 2036-2043. https://doi.org/10.1007/s11356-019-06612-x

Jones, R., Lee, S., Maybery, D., \& McFarlane, A. (2018). Experiences of a prolonged coal-mine fire. Disaster Prevention and Management, 27(5), 534-545. https://doi.org/10.1108/Dpm-05-2018-0145

Kioumourtzoglou, M. A., Power, M. C., Hart, J. E., Okereke, O. I., Coull, B. A., Laden, F., \& Weisskopf, M. G. (2017). The Association Between Air Pollution and Onset of Depression Among Middle-Aged and Older Women. American Journal of Epidemiology, 185(9), 801-809. https://doi.org/10.1093/aje/kww163

Knight, B. G., Gatz, M., Heller, K., \& Bengtson, V. L. (2000). Age and emotional response to the Northridge earthquake: a longitudinal analysis. Psychology and Aging, 15(4), 627-634. https://doi.org/10.1037/0882-7974.15.4.627

Kroll-Smith, J. S. a. C., S.R. (1990). The Real Disaster is Above Ground: A Mine Fire and Social Conflict. Lexington/Kentucky/USA: University Press of Kentucky.

Maybery, D., Jones, R., Dipnall, J. F., Berger, E., Campbell, T., McFarlane, A., \& Carroll, M. (2020). A mixedmethods study of psychological distress following an environmental catastrophe: the case of the Hazelwood open-cut coalmine fire in Australia. Anxiety Stress Coping, 33(2), 216-230. https://doi.org/10.1080/10615806.2019.1695523

Melody, S. M., \& Johnston, F. H. (2015). Coal mine fires and human health: What do we know? International Journal of Coal Geology, 152, 1-14. https://doi.org/10.1016/j.coal.2015.11.001

Newson, R. (2006). Confidence intervals for rank statistics: Percentile slopes, differences, and ratios. Stata Journal, 6(4), 497-520. https://doi.org/10.1177/1536867x0600600404

North, C. S., Hong, B. A., Suris, A., \& Spitznagel, E. L. (2008). Distinguishing distress and psychopathology among survivors of the Oakland/Berkeley firestorm. Psychiatry, 71(1), 35-45. https://doi.org/10.1521/psyc.2008.71.1.35

Novais, A., Monteiro, S., Roque, S., Correia-Neves, M., \& Sousa, N. (2017). How age, sex and genotype shape the stress response. Neurobiol Stress, 6, 44-56. https://doi.org/10.1016/j.ynstr.2016.11.004

Perrin, M., Vandeleur, C. L., Castelao, E., Rothen, S., Glaus, J., Vollenweider, P., \& Preisig, M. (2014). Determinants of the development of post-traumatic stress disorder, in the general population. Social Psychiatry and Psychiatric Epidemiology, 49(3), 447-457. https://doi.org/10.1007/s00127013-0762-3

Power, M. C., Kioumourtzoglou, M. A., Hart, J. E., Okereke, O. I., Laden, F., \& Weisskopf, M. G. (2015). The relation between past exposure to fine particulate air pollution and prevalent anxiety: observational cohort study. BMJ, 350, h1111. https://doi.org/10.1136/bmj.h1111

Ren, T., Yu, X., \& Yang, W. (2019). Do cognitive and non-cognitive abilities mediate the relationship between air pollution exposure and mental health? PloS One, 14(10), e0223353. https://doi.org/10.1371/journal.pone.0223353

Royston, P., \& White, I. R. (2011). Multiple Imputation by Chained Equations (MICE): Implementation in Stata. Journal of Statistical Software, 45(4), 1-20. https://doi.org/10.18637/jss.v045.i04

Rubin, D. B. (1996). Multiple imputation after 18+ years. Journal of the American Statistical Association, 91(434), 473-489. https://doi.org/10.2307/2291635

Sass, V., Kravitz-Wirtz, N., Karceski, S. M., Hajat, A., Crowder, K., \& Takeuchi, D. (2017). The effects of air pollution on individual psychological distress. Health Place, 48, 72-79. https://doi.org/10.1016/j.healthplace.2017.09.006

StataCorp. (2017). Stata Statistical Software: Release 15. College Station, TX: StataCorp LLC.

Weiss, D. S., \& Marmar, C. R. (1997). The Impact of Event Scale-Revised. In Assessing psychological trauma and PTSD (pp. 399-411). New York City, New York, USA: Guilford Press; US. 
Wood, P., Duffy, M., Yell, S., Morrissey, B., Whyte, S., Walker, L., \& Maybery, D. (2015). Coal mine fire initial impact on community health and wellbeing summary report. Retrieved from Churchill/Victoria/Australia:

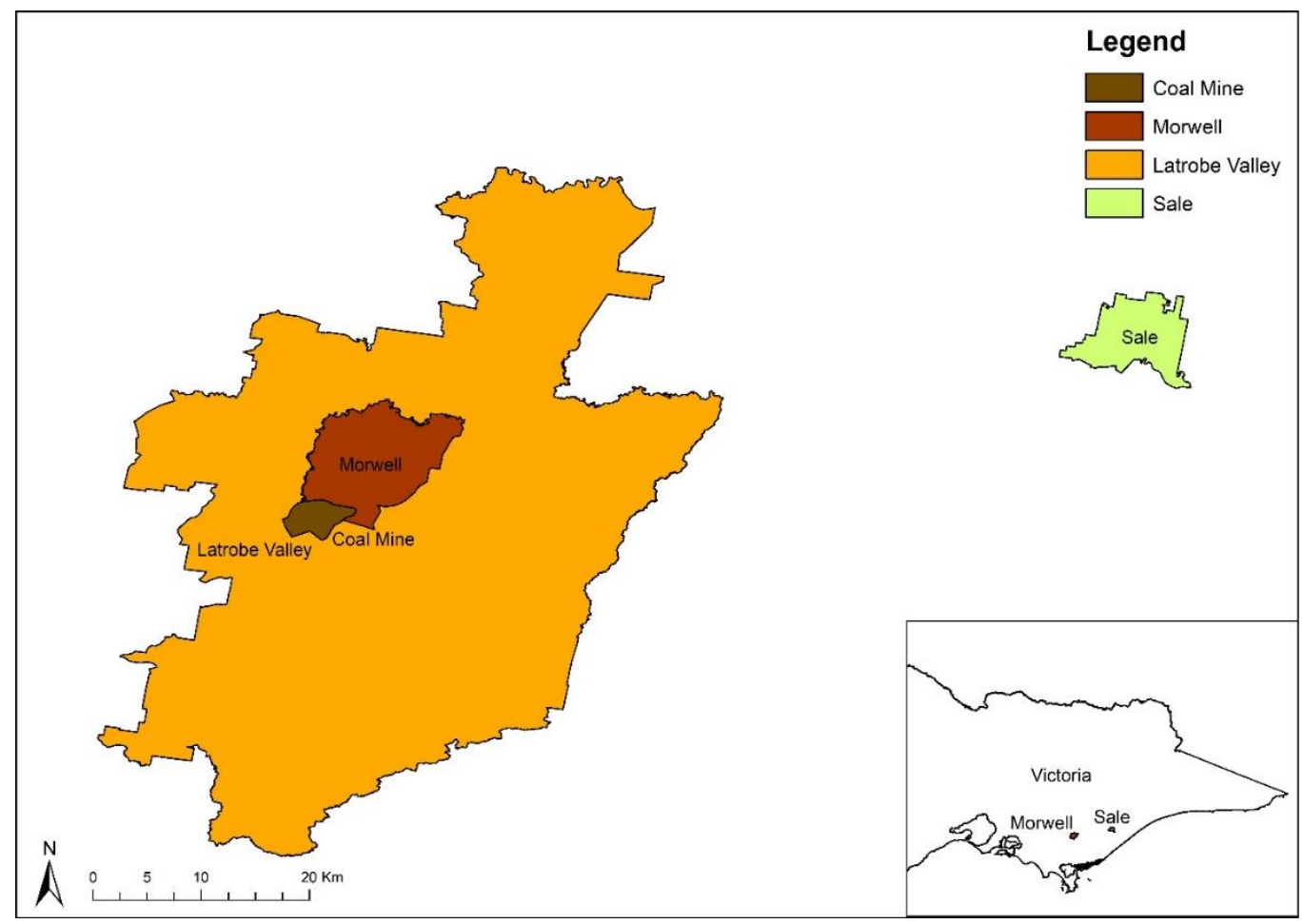

Figure 1. Relative locations of the coal mine, Morwell, wider Latrobe Valley, and Sale, and position with the state of Victoria, Australia. 
Table 1. Participants' characteristics by $\mathrm{PM}_{2.5}$ exposure - no exposure in Sale compared to mean $\mathrm{PM}_{2.5}$ tertiles in Morwell.

\begin{tabular}{|c|c|c|c|c|c|}
\hline & $\begin{array}{l}\text { Sale no exposure }{ }^{a} \\
\qquad N=960\end{array}$ & $\begin{array}{c}\text { Morwell low }^{a} \\
\text { exposure } \\
N=1053\end{array}$ & $\begin{array}{c}\text { Morwell medium }^{a} \\
\text { exposure } \\
\mathrm{N}=1027\end{array}$ & $\begin{array}{l}\text { Morwell high }^{a} \\
\text { exposure } \\
\mathrm{N}=1016\end{array}$ & \\
\hline & $\mathrm{n}(\%)^{b}$ & $\mathrm{n}(\%)^{b}$ & $\mathrm{n}(\%)^{b}$ & $\mathrm{n}(\%)^{b}$ & $p$-value \\
\hline Male & $410(45 \%)$ & 459 (47\%) & $471(50 \%)$ & $459(47 \%)$ & 0.185 \\
\hline \multicolumn{6}{|l|}{ Employment } \\
\hline Paid employment & $451(56 \%)$ & 432 (51\%) & $444(52 \%)$ & 435 (51\%) & $<0.001$ \\
\hline $\begin{array}{l}\text { Student/volunteer/home- } \\
\text { duties/retired }\end{array}$ & $431(37 \%)$ & 485 (37\%) & $439(33 \%)$ & $444(36 \%)$ & \\
\hline Unemployed & $19(3 \%)$ & $50(6 \%)$ & $50(7 \%)$ & $39(5 \%)$ & \\
\hline Unable to work & $44(4 \%)$ & $68(6 \%)$ & $83(7 \%)$ & $88(8 \%)$ & \\
\hline \multicolumn{6}{|l|}{ Highest educational } \\
\hline Up to year 10 & $241(21 \%)$ & $332(26 \%)$ & $360(29 \%)$ & $314(26 \%)$ & $<0.001$ \\
\hline Secondary year 11-12 & $162(18 \%)$ & 207 (22\%) & $240(26 \%)$ & $221(23 \%)$ & \\
\hline $\begin{array}{l}\text { Certificate (trade/ } \\
\text { apprenticeship/technical) }\end{array}$ & $379(42 \%)$ & $359(35 \%)$ & $300(32 \%)$ & 337 (35\%) & \\
\hline $\begin{array}{l}\text { University or other Tertiary } \\
\text { Institute degree }\end{array}$ & $167(20 \%)$ & 139 (16\%) & $112(12 \%)$ & $134(15 \%)$ & \\
\hline Prior mental health conditions & $263(26 \%)$ & $285(27 \%)$ & $298(29 \%)$ & $296(30 \%)$ & 0.286 \\
\hline \multicolumn{6}{|l|}{ Number of traumatic life events } \\
\hline None & $306(36 \%)$ & $326(34 \%)$ & $351(37 \%)$ & $298(32 \%)$ & 0.123 \\
\hline One & 207 (22\%) & $220(21 \%)$ & $202(20 \%)$ & $188(18 \%)$ & \\
\hline Multiple & $430(42 \%)$ & $493(45 \%)$ & 457 (44\%) & $505(50 \%)$ & \\
\hline \multicolumn{6}{|l|}{ Cardiovascular disease } \\
\hline No & $728(81 \%)$ & 808 (83\%) & $765(80 \%)$ & $734(78 \%)$ & 0.274 \\
\hline Yes, pre-fire & $178(15 \%)$ & 185 (14\%) & $192(15 \%)$ & 207 (16\%) & \\
\hline Yes, post-fire & $42(4 \%)$ & 47 (4\%) & $58(5 \%)$ & $56(5 \%)$ & \\
\hline \multicolumn{6}{|l|}{ Asthma } \\
\hline No & $743(76 \%)$ & $774(71 \%)$ & $764(72 \%)$ & 767 (74\%) & 0.025 \\
\hline Yes, pre-fire & $205(23 \%)$ & $253(27 \%)$ & $241(26 \%)$ & $221(24 \%)$ & \\
\hline Yes, post-fire & $7(1 \%)$ & $21(2 \%)$ & $18(2 \%)$ & $20(2 \%)$ & \\
\hline \multicolumn{6}{|l|}{ COPD } \\
\hline No & $914(97 \%)$ & 983 (95\%) & 961 (95\%) & 934 (94\%) & 0.057 \\
\hline Yes, pre-fire & $27(2 \%)$ & $46(3 \%)$ & $44(3 \%)$ & $58(4 \%)$ & \\
\hline Yes, post-fire & $15(1 \%)$ & $21(1 \%)$ & $20(1 \%)$ & $19(1 \%)$ & \\
\hline \multicolumn{6}{|l|}{ Binge drinking } \\
\hline Never & $608(58 \%)$ & 712 (62\%) & 677 (59\%) & 695 (64\%) & 0.547 \\
\hline Less than monthly & $186(24 \%)$ & $192(22 \%)$ & $192(24 \%)$ & $161(20 \%)$ & \\
\hline Monthly & 76 (10\%) & $68(9 \%)$ & 66 (9\%) & 72 (9\%) & \\
\hline Weekly & $58(8 \%)$ & $45(5 \%)$ & $60(6 \%)$ & $49(5 \%)$ & \\
\hline Daily or almost daily & $13(1 \%)$ & $15(1 \%)$ & $14(1 \%)$ & $13(1 \%)$ & \\
\hline \multicolumn{6}{|l|}{ Occupational exposure } \\
\hline Not exposed & $608(65 \%)$ & 637 (64\%) & $613(63 \%)$ & $575(59 \%)$ & $<0.001$ \\
\hline Coal mine/station exposed & $29(3 \%)$ & $167(14 \%)$ & $152(12 \%)$ & $175(16 \%)$ & \\
\hline \multirow{2}{*}{$\begin{array}{l}\text { Exposed, but not coal } \\
\text { mine/station }\end{array}$} & $323(32 \%)$ & $249(22 \%)$ & $262(25 \%)$ & $266(25 \%)$ & \\
\hline & Mean (SD) ${ }^{a}$ & Mean (SD) ${ }^{a}$ & Mean (SD) ${ }^{a}$ & Mean (SD) ${ }^{a}$ & \\
\hline Age & $50.3(16.9)$ & $50.4(19.8)$ & $49.4(18.9)$ & $51.9(20.0)$ & 0.168 \\
\hline Mean exposure to $\mu \mathrm{g} / \mathrm{m}^{3} \mathrm{PM}_{2.5}$ & $0.1(0.5)$ & $6.2(2.0)$ & $11.4(1.7)$ & $27.7(11.8)$ & $<0.001$ \\
\hline \multirow[t]{2}{*}{ Peak exposure to $\mu \mathrm{g} / \mathrm{m}^{3} \mathrm{PM}_{2.5}$} & $4.6(31.8)$ & $94.9(52.0)$ & $155.8(91.7)$ & $442.9(252.0)$ & $<0.001$ \\
\hline & Median (IQR) ${ }^{a}$ & Median (IQR) ${ }^{a}$ & Median (IQR) ${ }^{a}$ & Median (IQR) ${ }^{a}$ & \\
\hline IES-R & $0.0(0.0-0.0)$ & $1.0(0.0-10.0)$ & $1.0(0.0-12.0)$ & $3.0(0.0-17.0)$ & $<0.001$ \\
\hline
\end{tabular}


${ }^{a}$ Morwell participants were grouped by mean $\mathrm{PM}_{2.5}$ exposure tertiles and Sale participants were the no exposure comparison group. However, some participants from Sale would have had some $\mathrm{PM}_{2.5}$ exposure, and some participants from Morwell would have had no $\mathrm{PM}_{2.5}$ exposure.

${ }^{b} \%$, Mean, SD, Median and IQR were weighted.

${ }^{c}$ Proportion of missing observations for each IES-R item ranged from $1.85 \%$ to $3.13 \%$ of study sample (4056). IESR-R had 235 (5.79\%) missing observations, sex had 2 (0.05\%) missing observations, employment status had 54 (1.33\%) missing observations, highest education had 52 (1.28\%) missing observations, prior mental health had $19(0.47 \%)$ missing observations, number of traumatic life events had 73 (1.80\%) missing observations, cardiovascular disease had 56 (1.38\%) missing observations, asthma had 22 (0.54\%) missing observations, COPD had $14(0.35 \%)$ missing observations, binge drinking had 84 missing observations (2.07\%), occupational exposure had 0 missing observations, age had 6 missing observations (0.15\%), and mean and peak exposure to $\mathrm{PM}_{2.5}$ had 0 missing observations.

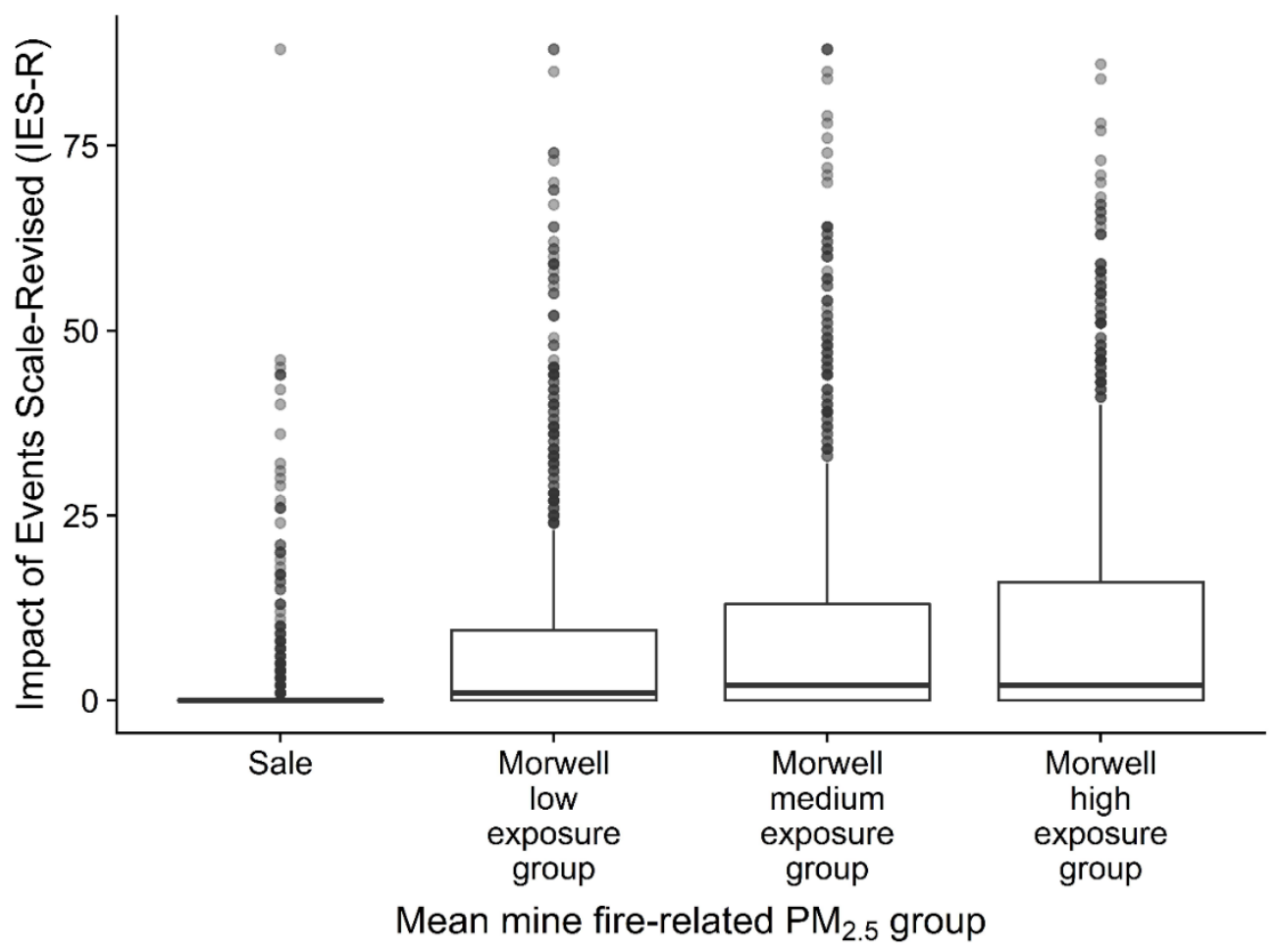

Figure 2. Box plot of IES-R scores by exposure groups defined as Sale compared with tertiles of mean exposure to $\mathrm{PM}_{2.5}$ within Morwell. IES-R scores were not weighted in Figure 2. 


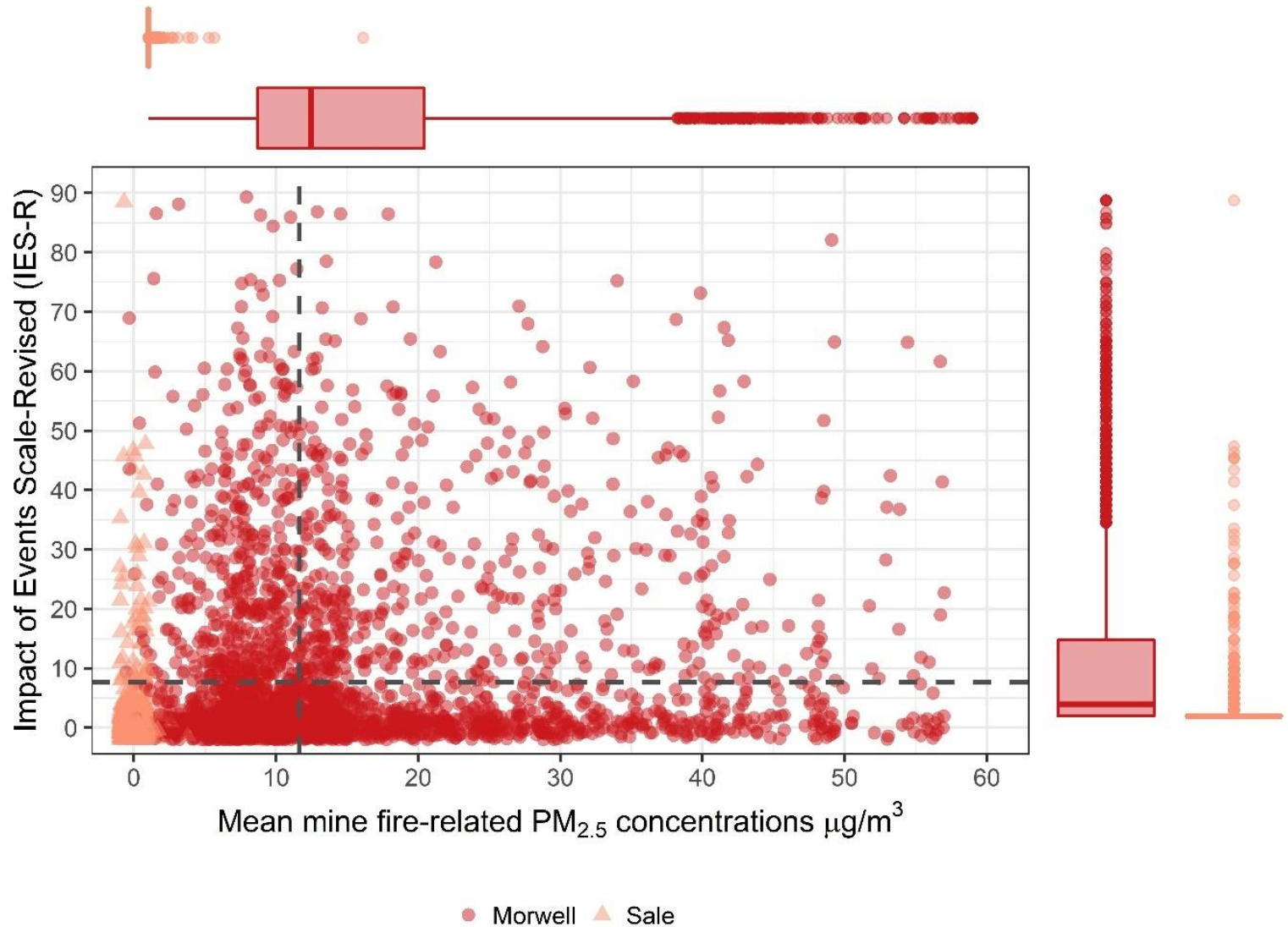

Figure 3. Scatter plot of mean exposure to $\mathrm{PM}_{2.5}\left(\mu \mathrm{g} / \mathrm{m}^{3}\right)$ with IESR by group with marginal distribution by the side. The dotted line across the vertical axis reflects the mean of IESR-R scores and the dotted line across the horizontal axis reflects the mean of mean exposure to $\mathrm{PM}_{2.5}$. 


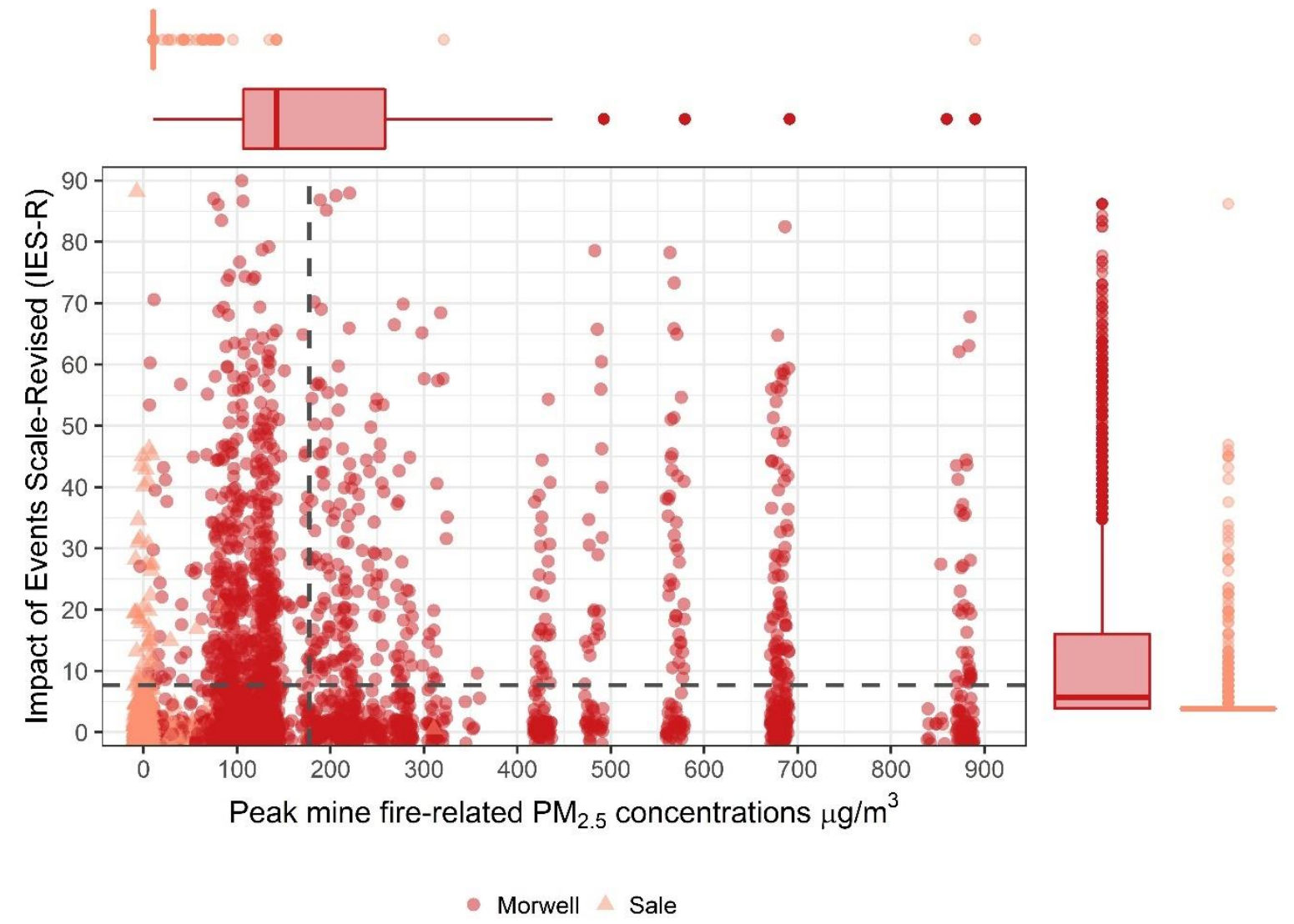

Figure 4. Scatter plot of peak exposure to $\mathrm{PM}_{2.5}\left(\mu \mathrm{g} / \mathrm{m}^{3}\right)$ with IESR by group with marginal distribution by the side. The dotted line across the vertical axis reflects the mean of IESR-R scores and the dotted line across the horizontal axis reflects the mean of peak exposure to $\mathrm{PM}_{2.5}$. 
Table 2. Association between IES-R scores with $\mathrm{PM}_{2.5}$ exposure and confounding variables.

\begin{tabular}{|c|c|c|c|c|}
\hline \multirow[b]{2}{*}{ Predictors } & \multicolumn{2}{|c|}{$\begin{array}{l}\text { Mean } \mathrm{PM}_{2.5} \text { exposure } \\
\text { Regression model }\end{array}$} & \multicolumn{2}{|c|}{$\begin{array}{c}\text { Peak PM2.5 exposure Regression } \\
\text { model }^{b}\end{array}$} \\
\hline & $\begin{array}{c}\text { IES-R } \\
\text { Adj coefficient } \\
(95 \% \mathrm{Cl})\end{array}$ & $p$-value & $\begin{array}{c}\text { IES-R } \\
\text { Adj coefficient } \\
(95 \% \mathrm{Cl})\end{array}$ & $p$-value \\
\hline $\mathrm{PM}_{2.5}$ exposure & $0.98(0.36,1.61)$ & 0.002 & $0.36(0.06,0.67)$ & 0.019 \\
\hline $\operatorname{Age}^{c}$ & $-0.47(-0.80,-0.13)$ & 0.007 & $-0.44(-0.76,-0.11)$ & 0.009 \\
\hline Interaction between exposure and age & $-0.26(-0.52,-0.01)$ & 0.043 & $-0.05(-0.19,0.09)$ & 0.497 \\
\hline Any mental health conditions & $1.66(0.54,2.78)$ & 0.004 & $1.69(0.57,2.82)$ & 0.003 \\
\hline Male & $-0.62(-1.65,0.40)$ & 0.234 & $-0.61(-1.64,0.43)$ & 0.249 \\
\hline Morwell & $5.47(4.25,6.68)$ & $<0.001$ & $6.25(5.23,7.26)$ & $<0.001$ \\
\hline \multicolumn{5}{|l|}{ Cardiovascular disease ${ }^{d}$} \\
\hline Yes, pre-fire & $0.64(-0.67,1.94)$ & 0.340 & $0.64(-0.65,1.94)$ & 0.331 \\
\hline Yes, post-fire & $0.36(-1.78,2.50)$ & 0.743 & $0.34(-1.81,2.48)$ & 0.759 \\
\hline \multicolumn{5}{|l|}{ Asthma ${ }^{d}$} \\
\hline Yes, pre-fire & $1.53(0.43,2.64)$ & 0.006 & $1.46(0.35,2.57)$ & 0.010 \\
\hline Yes, post-fire & $5.23(1.28,9.18)$ & 0.010 & $5.21(1.23,9.19)$ & 0.010 \\
\hline \multicolumn{5}{|l|}{$\operatorname{COPD}^{d}$} \\
\hline Yes, pre-fire & $4.92(1.30,8.53)$ & 0.008 & $4.80(1.19,8.41)$ & 0.009 \\
\hline Yes, post-fire & $6.13(0.84,11.41)$ & 0.023 & $6.11(0.82,11.41)$ & 0.024 \\
\hline \multicolumn{5}{|l|}{ Number of traumatic life events ${ }^{d}$} \\
\hline One & $-0.34(-1.45,0.77)$ & 0.551 & $-0.39(-1.50,0.73)$ & 0.495 \\
\hline Multiple & $2.58(1.49,3.67)$ & $<0.001$ & $2.59(1.49,3.69)$ & $<0.001$ \\
\hline \multicolumn{5}{|l|}{ Highest educational qualification ${ }^{d}$} \\
\hline Secondary year $11-12$ & $-2.21(-3.68,-0.74)$ & 0.003 & $-2.13(-3.60,-0.66)$ & 0.004 \\
\hline Certificate (trade/ apprenticeship/technicians) & $-2.85(-4.16,-1.54)$ & $<0.001$ & $-2.82(-4.13,-1.51)$ & $<0.001$ \\
\hline University or other Tertiary Institute degree & $-3.36(-4.86,-1.86)$ & $<0.001$ & $-3.35(-4.86,-1.83)$ & $<0.001$ \\
\hline \multicolumn{5}{|l|}{ Employment $^{d}$} \\
\hline Other (student/volunteer/home-duties/retired) & $0.39(-0.75,1.54)$ & 0.498 & $0.52(-0.64,1.68)$ & 0.380 \\
\hline Unemployed & $4.21(0.99,7.43)$ & 0.010 & $4.36(1.14,7.59)$ & 0.008 \\
\hline Unable to work & $4.72(2.34,7.09)$ & $<0.001$ & $5.02(2.64,7.39)$ & $<0.001$ \\
\hline \multicolumn{5}{|l|}{ Binge drinking ${ }^{d}$} \\
\hline Less than monthly & $-0.04(-1.23,1.15)$ & 0.949 & $-0.09(-1.29,1.11)$ & 0.886 \\
\hline Monthly & $0.88(-0.77,2.53)$ & 0.296 & $0.79(-0.87,2.44)$ & 0.352 \\
\hline Weekly & $-0.39(-2.11,1.34)$ & 0.661 & $-0.49(-2.24,1.27)$ & 0.587 \\
\hline Daily or almost daily & $-0.88(-4.88,3.12)$ & 0.666 & $-0.91(-4.87,3.05)$ & 0.653 \\
\hline \multicolumn{5}{|l|}{ Occupational exposure } \\
\hline Coal mine/station exposed & $0.56(-1.12,2.24)$ & 0.516 & $0.60(-1.08,2.28)$ & 0.484 \\
\hline Exposed, but not coal mine/station & $0.22(-0.86,1.29)$ & 0.693 & $0.24(-0.84,1.31)$ & 0.666 \\
\hline \multicolumn{5}{|c|}{$\begin{array}{l}{ }^{d} \text { The lowest level for each variable was used as the reference condition, i.e. no cardiovascular disease, no asthma, no } \\
\text { COPD, no traumatic life events, education up to year 10, paid employment, no binge drinking, and not exposed. } \\
{ }^{\text {e }} \text { The association between IES-R scores with } \mathrm{PM}_{2.5} \text { is adjusted for age, sex, employment, education, prior mental } \\
\text { health conditions, prior traumatic exposures, asthma, COPD, cardiac events, frequency of binge drinking, occupational } \\
\text { exposure, and township of residence. Mean and peak PM2.5 exposure were modelled separately using two regression } \\
\text { models which both accounted for post-stratification weights as well as clustering at the household level. }\end{array}$} \\
\hline
\end{tabular}




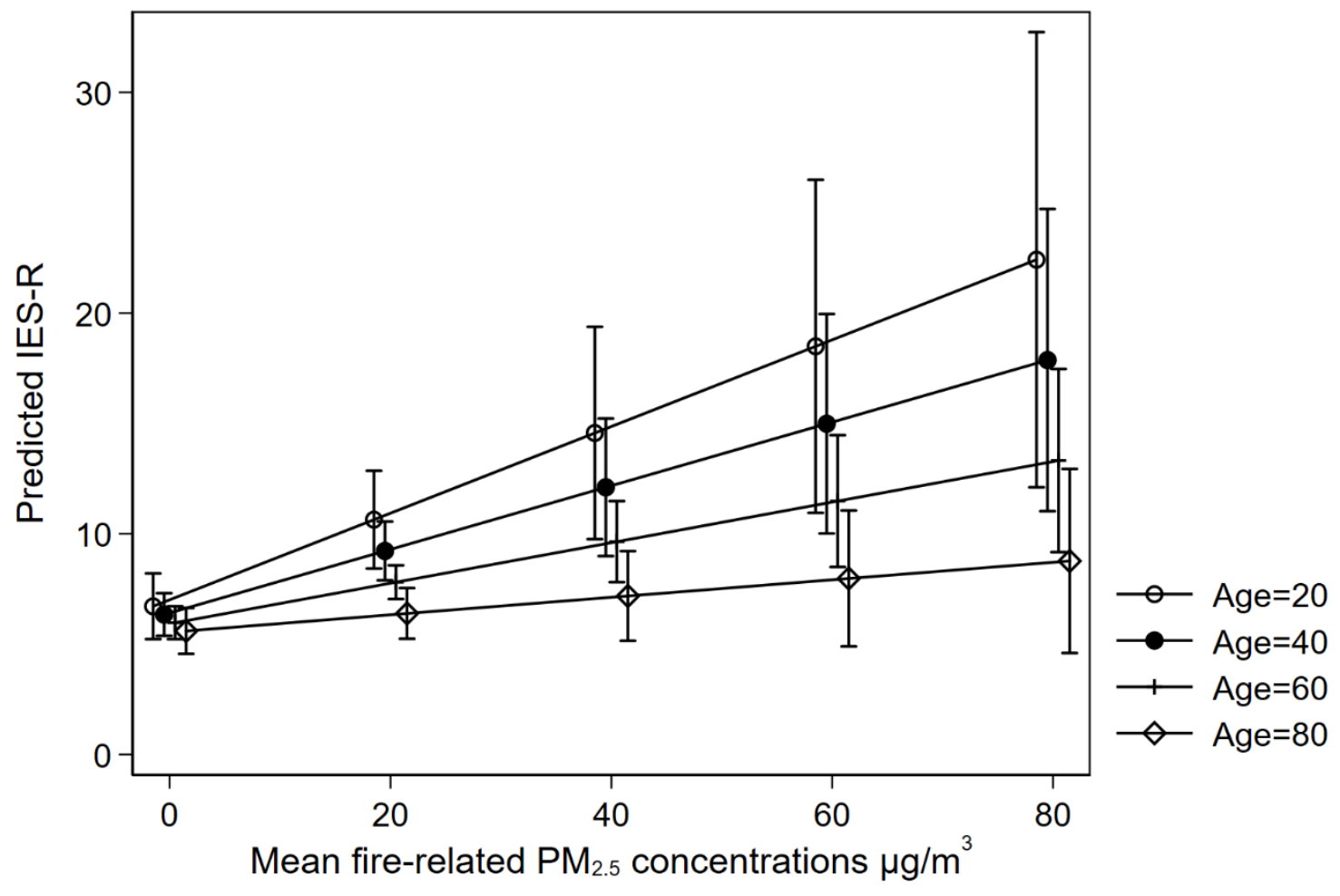

Figure 5. Predictive marginal plot for mean exposure to $\mathrm{PM}_{2.5}\left(\mu \mathrm{g} / \mathrm{m}^{3}\right)$ and IES-R by age group. Error bars reflect $95 \%$ confidence intervals of IES-R for each age group across exposure levels. 


\section{Supplementary Material}

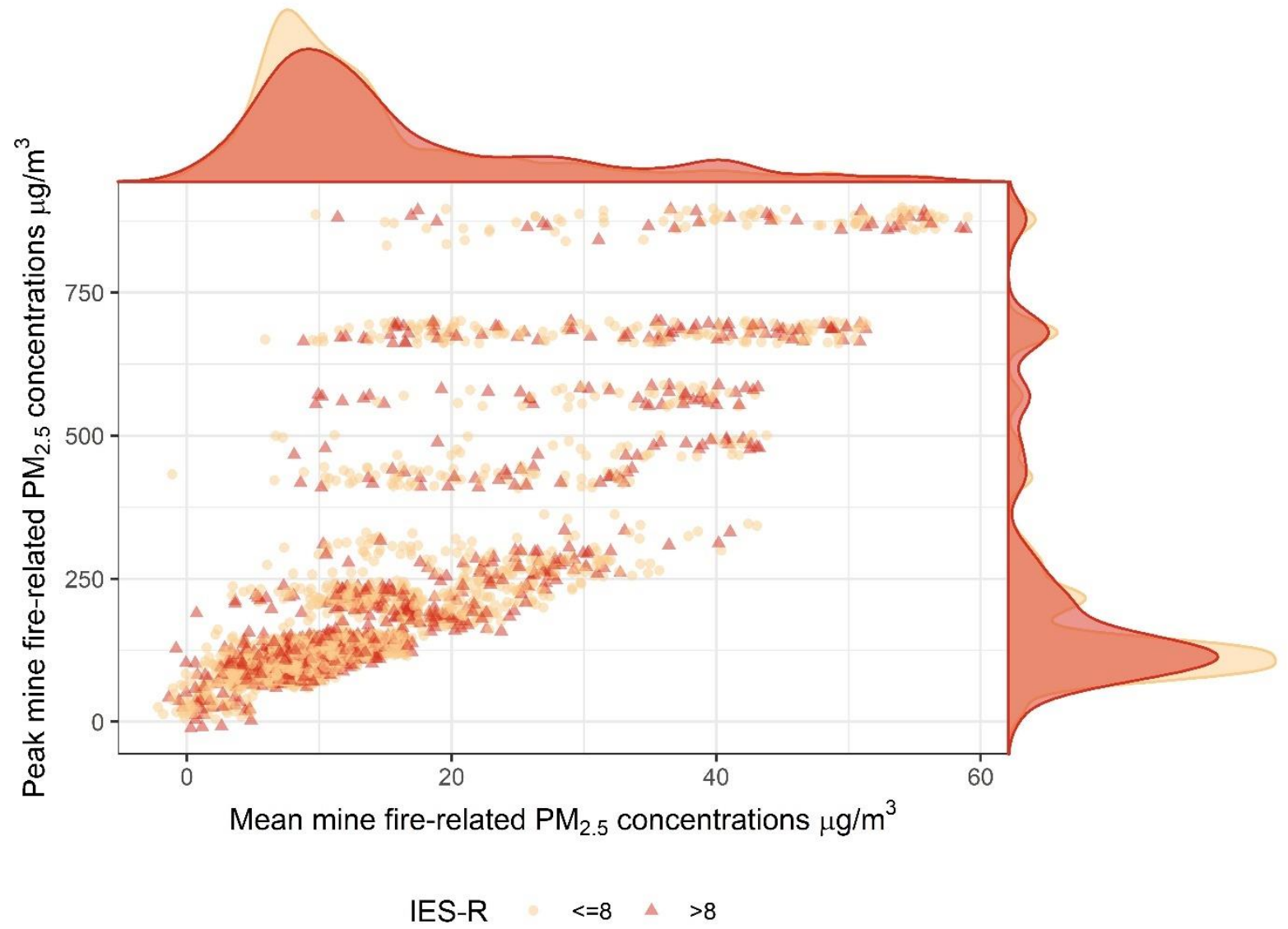

Figure S 1. Scatter plot and distribution of mean and peak exposure to $\mathrm{PM}_{2.5}\left(\mu \mathrm{g} / \mathrm{m}^{3}\right)$ by IES-R group (IES-R $\leq$ 8 vs IES-R > 8) for Morwell residents only. 
Table S 1. Association between IES-R scores with $\mathrm{PM}_{2.5}$ exposure and confounding variables in Morwell only.

${ }^{a}$ Mean $P M_{2.5}$ exposure per $10 \mu \mathrm{g} / \mathrm{m}^{3}$ and centred at $10 \mu \mathrm{g} / \mathrm{m}^{3}$.

\begin{tabular}{|c|c|c|c|c|}
\hline \multirow[t]{2}{*}{ Predictors } & \multicolumn{2}{|c|}{$\begin{array}{l}\text { Mean } \mathrm{PM}_{2.5} \text { exposure } \\
\text { Regression model }{ }^{\mathrm{a}}\end{array}$} & \multicolumn{2}{|c|}{$\begin{array}{l}\text { Peak PM } 2.5 \text { exposure } \\
\text { Regression model }{ }^{b}\end{array}$} \\
\hline & $\begin{array}{c}\text { IES-R } \\
\text { Adj coefficient }{ }^{\text {e }} \\
(95 \% \mathrm{Cl})\end{array}$ & $p$-value & $\begin{array}{c}\text { IES-R } \\
\text { Adj coefficient }{ }^{\text {e }} \\
(95 \% \mathrm{Cl})\end{array}$ & $p$-value \\
\hline $\mathrm{PM}_{2.5}$ exposure & $0.92(0.32,1.53)$ & 0.003 & $0.36(0.06,0.66)$ & 0.020 \\
\hline Age $^{c}$ & $-0.30(-0.80,0.20)$ & 0.245 & $-0.41(-0.93,0.11)$ & 0.123 \\
\hline Interaction between exposure and age & $-0.45(-0.79,-0.10)$ & 0.012 & $-0.09(-0.27,0.08)$ & 0.301 \\
\hline Any mental health conditions & $2.53(1.04,4.02)$ & $<0.001$ & $2.59(1.10,4.09)$ & $<0.001$ \\
\hline Male & $-0.73(-2.14,0.69)$ & 0.314 & $-0.71(-2.13,0.71)$ & 0.329 \\
\hline \multicolumn{5}{|l|}{ Cardiovascular disease $^{d}$} \\
\hline Yes, pre-fire & $0.53(-1.24,2.29)$ & 0.558 & $0.52(-1.23,2.28)$ & 0.559 \\
\hline Yes, post-fire & $-0.17(-2.93,2.59)$ & 0.904 & $-0.22(-3.00,2.55)$ & 0.875 \\
\hline \multicolumn{5}{|l|}{ Asthma ${ }^{d}$} \\
\hline Yes, pre-fire & $2.21(0.73,3.70)$ & 0.004 & $2.06(0.57,3.55)$ & 0.007 \\
\hline Yes, post-fire & $5.32(1.10,9.53)$ & 0.013 & $5.25(0.99,9.50)$ & 0.016 \\
\hline \multicolumn{5}{|l|}{$\mathrm{COPD}^{d}$} \\
\hline Yes, pre-fire & $5.94(1.54,10.34)$ & 0.008 & $5.77(1.36,10.18)$ & 0.010 \\
\hline Yes, post-fire & $8.28(1.54,15.02)$ & 0.016 & $8.34(1.57,15.10)$ & 0.016 \\
\hline \multicolumn{5}{|l|}{ Number of traumatic life events ${ }^{d}$} \\
\hline One & $-0.40(-1.96,1.16)$ & 0.617 & $-0.53(-2.09,1.04)$ & 0.508 \\
\hline Multiple & $3.09(1.59,4.60)$ & $<0.001$ & $3.08(1.56,4.59)$ & $<0.001$ \\
\hline \multicolumn{5}{|l|}{ Highest educational qualification ${ }^{d}$} \\
\hline $\begin{array}{l}\text { Secondary year } 11-12 \\
\text { Certificate (trade/ }\end{array}$ & $-2.57(-4.43,-0.71)$ & 0.007 & $-2.51(-4.37,-0.65)$ & 0.008 \\
\hline $\begin{array}{l}\text { apprenticeship/technicians) } \\
\text { University or }\end{array}$ & $-3.52(-5.22,-1.82)$ & $<0.001$ & $-3.50(-5.21,-1.79)$ & $<0.001$ \\
\hline degree & $-4.57(-6.61,-2.54)$ & $<0.001$ & $-4.59(-6.65,-2.54)$ & $<0.001$ \\
\hline \multicolumn{5}{|l|}{ Employment $^{d}$} \\
\hline $\begin{array}{l}\text { Other (student/volunteer/home- } \\
\text { duties/retired) }\end{array}$ & $0.67(-0.94,2.28)$ & 0.417 & $0.88(-0.76,2.51)$ & 0.293 \\
\hline Unemployed & $4.20(0.68,7.72)$ & 0.019 & $4.37(0.82,7.91)$ & 0.016 \\
\hline Unable to work & $4.74(1.84,7.64)$ & 0.001 & $5.19(2.29,8.09)$ & $<0.001$ \\
\hline \multicolumn{5}{|l|}{ Binge drinking $^{d}$} \\
\hline Less than monthly & $0.16(-1.48,1.81)$ & 0.847 & $0.08(-1.58,1.73)$ & 0.928 \\
\hline Monthly & $1.12(-1.22,3.47)$ & 0.348 & $0.92(-1.43,3.27)$ & 0.444 \\
\hline Weekly & $-0.44(-2.96,2.08)$ & 0.733 & $-0.59(-3.17,2.00)$ & 0.656 \\
\hline Daily or almost daily & $-0.21(-6.02,5.60)$ & 0.944 & $-0.25(-6.02,5.52)$ & 0.933 \\
\hline \multicolumn{5}{|l|}{ Occupational exposure } \\
\hline Coal mine/station exposed & $0.49(-1.52,2.50)$ & 0.632 & $0.66(-1.35,2.67)$ & 0.521 \\
\hline Exposed, but not coal mine/station & $0.37(-1.16,1.90)$ & 0.637 & $0.42(-1.12,1.95)$ & 0.595 \\
\hline
\end{tabular}

Peak PM2.5 exposure per $100 \mu \mathrm{g} / \mathrm{m}^{3}$ and centred at $100 \mu \mathrm{g} / \mathrm{m}^{3}$.

${ }^{c}$ Age per 10 years and centred at the mean (57 years).

${ }^{d}$ The lowest level for each variable was used as the reference condition, i.e. no cardiovascular disease, no asthma, no COPD, no traumatic life events, education up to year 10, paid employment, no binge drinking, and not exposed.

${ }^{\mathrm{e}}$ The association between IES-R scores with $\mathrm{PM}_{2.5}$ is adjusted for age, sex, employment, education, prior mental health conditions, prior traumatic exposures, asthma, COPD, cardiac events, frequency of binge drinking, occupational exposure, and township of residence. Mean and peak $\mathrm{PM}_{2.5}$ exposure were modelled separately using two regression models which both accounted for post-stratification weights as well as clustering at the household level. 


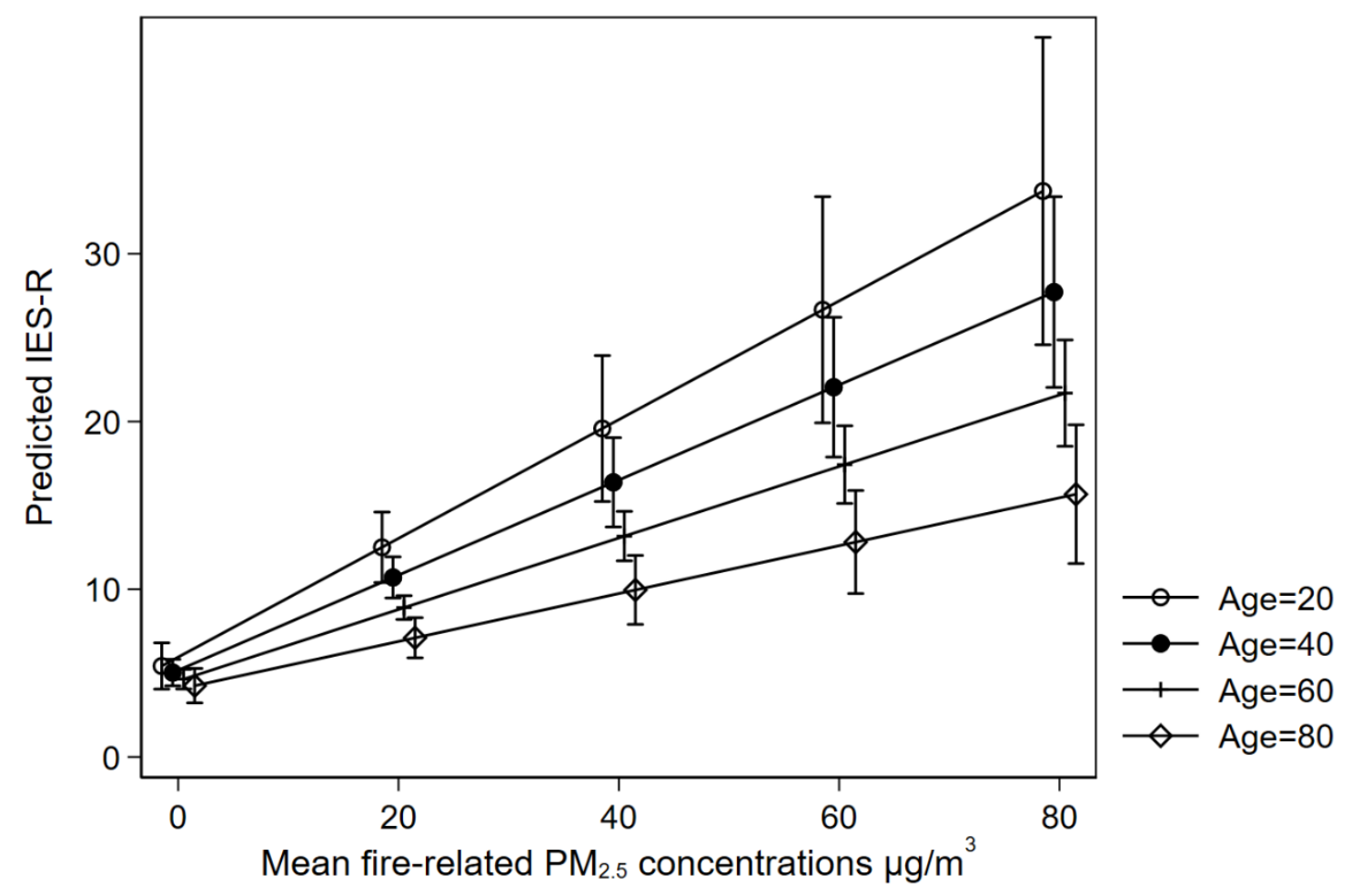

Figure S 2. Predictive marginal plot for mean exposure to $P M_{2.5}\left(\mu \mathrm{g} / \mathrm{m}^{3}\right)$ and IES-R by age group in Morwell only. Error bars reflect $95 \%$ confidence intervals of IES-R for each age group across exposure levels. 